\title{
Pengaruh Latihan Jump Shoot dan Bank Shoot Terhadap Kemampuan Shooting Pemain Klub Mranggen Selection Basketball
}

\author{
Ferdila Oktaviasari ${ }^{1}$, Galih Dwi Pradipta ${ }^{2}$, Maftukhin Hudah ${ }^{3}$ \\ ${ }^{123}$ Universitas Pgri Semarang. Jln Gajah Raya No 40. Semarang. 50166 \\ Coressponding Author. E-mail: ferdilaokta14@gmail.com
}

\begin{abstract}
The background of the problem in this study is the basketball club activity, Mranggen Selection Basketball, although in this study it is not directed to see the difference in a skill, but in plain view it is clear that there is a difference in the level of mastering the basic technique of shooting basketball. There are those who are good, moderate, and there are those who have not mastered shooting techniques optimally. As seen when shooting, the child was not maximal. Because there were problems when the students were shooting for the jump shoot, the child's accuracy level had not yet reached its peak. The research method used is quantitative research using true experimental method in the form of pretest-posttest control group design with two kinds of treatments. The population in this study were children who participated in the basketball club in Mranggen Selection Basketball. The sample in this study is the total population sampled for research with a total of 20 respondents. The sampling technique in this study used purposive sampling. The results of the study showed that the shooting exercise jumped on the basketball club participants. After giving push up and squat jump treatment, there was an increase in the shooting result, which was 5.30 where previously it was only 3.10. Through jump shoot practice, players are able to regulate the power or strength of the ball push properly so that the accuracy in shooting is more targeted. The conclusion of this study is that there is a significant effect of training with a jump shoot on shooting skills, there is a significant effect of training with a bank shoot on shooting skills.
\end{abstract}

Key words: Jump Shoot, Bank Shoot, Shooting

\begin{abstract}
Abstrak
Latar belakang masalah pada penelitian ini yaitu pada kegiatan klub bola basket, Mranggen Selection Basketball walaupun dalam penelitian ini tidak diarahkan untuk melihat perbedaan suatu keterampilan tetapi secara kasat mata jelas terlihat adanya perbedaan tingkat dalam menguasai teknik dasar shooting bola basket. Ada yang sudah bagus,sedang, dan ada yang belum menguasai teknik shooting secara optimal. Seperti terlihat ketika melakukan shooting, anak kurang maksimal, Karena ada masalah pada saat siswa shooting untuk jump shoot tingkat akurasinya anak masih belum mencapai puncaknya. Metode penelitian ini yang digunakan yaitu penelitian kuantitatif yang menggunakan metode true eksperimental dalam bentuk pretest-posttest control group design dengan dua macam perlakuan. Populasi dalam penelitian ini adalah anak mengikuti klub bola basket di Mranggen Selection Basketball. Sampel dalam penelitian ini adalah jumlah keseluruhan populasi dijadikan sampel untuk penelitian dengan jumlah 20 responden. Teknik sampling pada penelitian ini menggunakan purposive sampling. Hasil penelitian menunjukkan latihan Jump shoot hasil shooting pada peserta klub mranggen basketball. Setelah di beri perlakuan / Treatment push up dan squat jump terdapat peningkatan hasil shooting adalah 5,30 dimana sebelumnya hanya 3,10. Melalui latihan jump shoot pemain mampu mengatur tenaga atau kekuatan dorongan bola dengan baik sehingga akurasi dalam melakukan shooting lebih terarah. Simpulan penelitian ini adalah ada pengaruh signifikan latihan dengan jump shoot terhadap kemampuan shooting, ada pengaruh signifikan latihan dengan bank shoot terhadap kemampuan shooting.
\end{abstract}

Kata kunci : Jump Shoot, Bank Shoot, Shooting 


\section{PENDAHULUAN}

Secara umum pengertian olahraga adalah sebagai salah satu aktivitas fisik maupun psikis seseorang yang berguna untuk menjaga dan meningkatkan kualitas kesehatan seseorang tersebut setelah melakukan olahraga. Basketball adalah sebuah cabang olahraga yang dimana bola menjadi media utama dalam berjalannya sebuah permainan. Olahraga ini dilakukan oleh dua tim dan setiap tim terdiri dari 5 pemain. Cara bermain permainan ini adalah dengan memasukkan bola kedalam sebuah keranjang dan mengumpulkan poin sebanyak mungkin agar keluar menjadi pemenang. Nidhom Khoeron (2017: 1).

Jump shoot atau tembakan melompat merupakan tembakan yang paling sering digunakan dalam permainan bola basket. Tembakan ini harus dilakukan dengan gerakan melompat, kemudian pada puncaknya lompatan tersebut bola ditembakkan. Bank shoot adalah tembakan yang dilakukan oleh seorang pemain dengan memantulkan bola terlebih dahulu ke papan pantul sebelum masuk ke ring. Tembakan bank shoot bisa di lakukan pada sudut manapun kecuali pada sudut 0 derajat, sebab pada sudut ini tidak ada kemungkinan seorang pemain untuk melakukan tembakan dengan memantulkan bola ke papan pantul. Shooting adalah keterampilan dasar yang perlu dikuasai pemain. Banyak pemain yang secara khusus mencoba memposisikan diri untuk melatih shooting, terlepas dari tinggi maupun berat badan pemain, sangat disarankan untuk pemain memulai teknik shooting ini di segala posisi artinya bisa dari dekat atau dari posisi yang jauh dari keranjang. Renno Adiesta, Abdul Rachman Syam Tuasikal (2017: 3).

Melalui data hasil observasi yang dilakukan pada kegiatan klub bola basket, Mranggen Selection Basketball walaupun dalam penelitian ini tidak diarahkan untuk melihat perbedaan suatu keterampilan tetapi secara kasat mata jelas terlihat adanya perbedaan tingkat dalam menguasai teknik dasar shooting bola basket. Ada yang sudah bagus,sedang, dan ada yang belum menguasai teknik shooting secara optimal. Seperti terlihat ketika melakukan shooting, anak kurang maksimal, Karena ada masalah pada saat siswa shooting untuk jump shoot tingkat akurasinya anak masih belum mencapai puncaknya. Berdasarkan batasan masalah diatas, permasalahan yang diangkat dalam penelitian ini yaitu seberapa besar pengaruh latihan jump shoot terhadap hasil shooting bola basket di klub Mranggen Selection Basketball dengan bank shoot terhadap hasil shooting?

\section{METODE}

Penelitian ini dilakukan dengan menggunakan pendekatan kuantitatif yang menggunakan metode true eksperimental design. True experimental design yaitu jenis-jenis eskperimen yang dianggap sudah baik karena sudah memenuhi persyaratan. Yang dimaksud dengan persyaratan adalah adanya kelompok lain yang tidak dikenal eksperimen dan ikut mendapatkan pengamatan (Suharsimi Arikunto, 2014: 125). Desain yang digunakan dalam penelitian ini yaitu menggunakan true experimental design dalam bentuk protes-posttest control group design dengan dua macam perlakuan. 
Dalam penelitian ini penulis mengadakan percobaan terhadap sekelompok subjek yang akan dites kemampuan awalnya (pre-test) dalam melakukan shooting. Pelaksanaan penelitian ini menggunakan perlakuan atau treatment yang berbeda antara dua kelompok yaitu kelompok eksperimen 1 dan kelompok eksperimen 2. Dalam penelitian ini pengkelompokan ditentukan pada rangking tes awal. Pembagian kelompok dalam penelitian ini menggunakan model ordinal pairing. Setelah ditentukan kelompok eksperimen 1 diberi perlakuan berupa latihan jump shoot dan kelompok eksperimen 2 diberi perlakuan berupa latihan bank shoot. Perlakuan atau treatment diberikan selama 12 kali pertemuan yaitu termasuk tes awal (pre-test) dan dilakukan tes akhir (post-test) untuk mengetahui perbedaan pengaruh latihan jump shoot dan latihan bank shoot terhadap hasil shooting. Setelah kedua kelompok diberi perlakuan yang telah di rencanakan sebelumnya, kemudian data tes akhir (post-test) tersebut dibandingkan menggunakan statistic rumus pendek $t$-test.

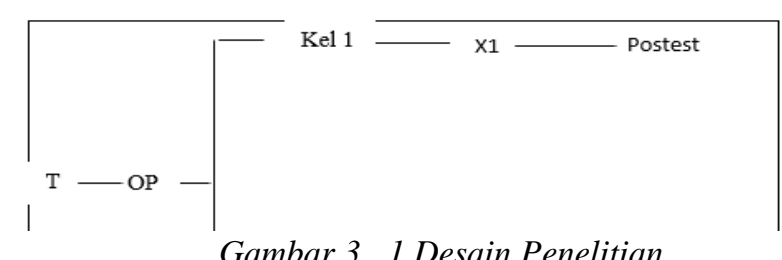

Gambar 3. 1 Desain Penelitian

\begin{tabular}{|c|c|}
\hline Keterangan & Kel $2-x_{2} \longrightarrow$ Pretest \\
\hline Pre-test(T) & : Tes awal shooting \\
\hline $\mathrm{OP}$ & : Ordinal pairing \\
\hline Kel1 & : Kelompok eksperimen 1 \\
\hline Kel2 & : Kelompok eksperimen 2 \\
\hline $\mathrm{X} 1$ & : Treatment jump shoot \\
\hline $\mathrm{X} 2$ & : Treatment bank shoot \\
\hline Post-test & : Tes akhir shooting \\
\hline
\end{tabular}

\section{HASIL DAN PEMBHASAN}

Metode latihan menggunakan jump shoot dan bank shoot terhadap kemampuan shooting pemain bola basket klub mranggen selection. Data diambil dengan tes shooting sebanyak 10 kali yang dilakukan sebelum dan sesudah treatment. Kegiatan peneliti secara keseluruhan dilakukan dalam tiga tahap yaitu, diawali dengan pre-test untuk mengetahui kemampuan awal pada sampel. Tahap kedua yaitu dengan latihan atau treatment latihan shooting dengan latihan metode jump shoot dan latihan metode bank shoot sebanyak 14 kali pertemuan. Tahap yang terakhir yaitu post-test untuk mengukur hasil shooting setelah diberi latihan atau treatment sesuai dengan program latihan. Adapun deskripsi dari data hasil pre-test dan post-test serta penguji hipotesis penelitian menggunakan uji t dapat disajikan sebagai berikut.

Penelitian ini merupakan penelitian deskriptif, yaitu penelitian yang hanya melukiskan keadaan 
objek. Data yang dimaksud dalam penelitian ini adalah data yang diperoleh dengan menggunakan metode pre test dan post test. Sebelum memberikan pre test dan post-test penelitian ini peneliti memberi masukan dan pengumuman maksud dan tujuan penelitian ini, hal ini dilakukan agar atlet dapat melakukan pre test dan post-test sesuai dengan keadaan sebenarnya dan bisa menjadi hasil penelitian yang valid. Apabila di tampilkan dalam bentuk deskripsi statistik, maka data Pengaruh Hasil Latihan Jump Shoot Dan Bank Shoot Terhadap Kemampuan Shooting Pemain Bola Basket Klub Mranggen Selection Basketball. Di bawah ini disajikan pada tabel sebagai berikut:

Tabel 1. Rata-Rata Treatment

\section{Case Summaries}

Rata-rata treatment

\begin{tabular}{|l|r|r|r|r|r|r|}
\hline Kelompok & $\mathrm{N}$ & \multicolumn{1}{|c|}{ Mean } & Std. Deviation & \multicolumn{1}{c|}{ Median } & Minimum & Maximum \\
\hline Jumpshoot & 10 & 20.0290 & 1.82918 & 20.6364 & 17.56 & 23.36 \\
Bankshoot & 10 & 11.2659 & 1.06889 & 11.3818 & 9.73 & 13.64 \\
Total & 20 & 15.6474 & 4.72598 & 15.5960 & 9.73 & 23.36 \\
\hline
\end{tabular}

Hasil pengukuran tersebut kemudian diolah secara deskriptif dan dapat diketahui pada masingmasing variabel. Variabel jump shoot nilai minumum yang diperoleh adalah 17.56, nilai maksimum adalah 23.36 dan nilai rata-rata 20 dengan standar deviasi 1,8. Hasil tes analisis deskriptif variabel bank shoot diketahui nilai minimum 9.73, nilai maksimum 13.64 dan rata-rata 11.2 dengan standar deviasi 1.06 .

1. Jumpshot dengan Pre test dan Post Test

Tabel 2. Jump Shot Dengan PreTest dan PostTest

Paired Samples Statistics

\begin{tabular}{|ll|r|r|r|c|}
\hline & & & & Std. Error \\
& & Mean & $\mathrm{N}$ & Std. Deviation & \multicolumn{1}{c|}{ Mean } \\
\hline Pair & Shooting pre & 3.10 & 10 & 1.524 & .482 \\
1 & Shooting post & 5.30 & 10 & 2.003 & .633 \\
\hline
\end{tabular}

Dapat diketahui pre-test dengan jumlah 10, memiliki rata rata 3.10, dengan stardart devisiasi 1.524. Dan post test dengan jumlah 10, memiliki rata rata 5.30, dengan memiliki standart devisiasi 2.003 .

2. Bank shoot dengan Pre-test dan Post-Test

Tabel 3. BankShot Dengan Pre Test dan Post Test

Paired Samples Statistics

\begin{tabular}{|ll|r|r|r|c|}
\hline & & Mean & $\mathrm{N}$ & Std. Deviation & $\begin{array}{c}\text { Std. Error } \\
\text { Mean }\end{array}$ \\
\hline Pair & Shooting pre & 2.80 & 10 & 1.135 & .359 \\
1 & Shooting post & 4.70 & 10 & 1.160 & .367 \\
\hline
\end{tabular}


Dapat diketahui pre test dengan jumlah 10, memiliki rata rata 2.80, dengan stardart devisiasi 1.135. Dan post-test dengan jumlah 10 , memiliki rata rata 4.70 , dengan memiliki standart devisiasi 1.160 .

A. Hasil Uji Homogenitas

Tabel 4. Hasil Uji Homogenitas Independent Samples Test

\begin{tabular}{|c|c|c|c|c|}
\hline & & & \multicolumn{2}{|c|}{ Rata-rata treatment } \\
\hline & & & $\begin{array}{l}\text { Equal variances } \\
\text { assumed }\end{array}$ & $\begin{array}{l}\text { Equal variances } \\
\text { not assumed }\end{array}$ \\
\hline \multirow{9}{*}{$\begin{array}{l}\text { Levene's Test for } \\
\text { Equality of Variances } \\
\text { t-test for Equality of } \\
\text { Means }\end{array}$} & \multicolumn{2}{|l|}{$\mathrm{F}$} & 3.617 & \\
\hline & \multicolumn{2}{|l|}{ Sig. } & .073 & \\
\hline & \multicolumn{2}{|l|}{$\mathrm{t}$} & 13.080 & 13.080 \\
\hline & \multicolumn{2}{|l|}{ df } & 18 & 14.505 \\
\hline & \multicolumn{2}{|l|}{ Sig. (2-tailed) } & .000 & .000 \\
\hline & \multicolumn{2}{|l|}{ Mean Difference } & 8.76318 & 8.76318 \\
\hline & \multicolumn{2}{|l|}{ Std. Error Difference } & 66996 & .66996 \\
\hline & \multirow{2}{*}{$\begin{array}{l}95 \% \text { Confidence Interval } \\
\text { of the Difference }\end{array}$} & Lower & 7.35566 & 7.33095 \\
\hline & & Upper & 10.17071 & 10.19542 \\
\hline
\end{tabular}

Pada hasil uji homogen pada uji t di atas diketahui nilainya 0,073 atau >0,05 sehingga dinyatakan variannya sama atau homogen. Sehinggan cocok dengan sampel penilitian atlet basket.

B. Hasil Uji Prasyarat

Uji prasyarat analisis data penelitian ditujukan untuk mengetahui data sudah memenuhi persyaratan analisis dalam pengujian hipotesis, yaitu meliputi uji normalitas data. Uji normalitas data dilakukan untuk mengetahui bahwa data tersebut berdistribusi normal atau data tidak berdistribusi normal.

Tabel 4. Hasil Uji Prasyarat

Tests of Normality

\begin{tabular}{|ll|r|r|r|}
\hline & & \multicolumn{3}{|c|}{ Shapiro-Wilk } \\
\cline { 3 - 5 } & Kelompok & Statistic & df & Sig. \\
\hline Rata-rata treatment & Jumpshoot & .905 & 10 & .249 \\
& Bankshoot & .910 & 10 & .284 \\
\hline
\end{tabular}

a. Lilliefors Significance Correction

Analisis Normalitas shapiro-wilk test menggunakan bantuan computer program SPSS versi 15 for windows. Berdasarkan tabel uji normalitas data diatas diketahui nilai signifikansi shapiro-wilk test pada jumpshoot adalah 0,611, nilai signifikansi shapiro-Wilk test pada bankshoot 0,284 , dimana signifikansi lebih besar > dari 0,05 maka dapat disimpulkan dari data tersebut dinyatakan data terdistribusi normal.

\section{Uji Hipotesis}

Uji hipotesis menggunakan analisis statistik korelasi pearson. Analisis korelasi menggunakan bantuan computer program SPSS versi 15 for windows dapat diperoleh data sebagai berikut: 
1. Jump shoot terhadap Shooting

Tabel 5. Jump Shoot Terhadap Shooting

Paired Samples Correlations

\begin{tabular}{|ll|r|r|r|}
\hline & & N & Correlation & \multicolumn{1}{c|}{ Sig. } \\
\hline Pair & Shooting pre \& & 10 & .899 & .000 \\
1 & Shooting post & 10 & .89 & \\
\hline
\end{tabular}

Hipotesis dalam penelitian tentang hubungan jump shoot terhadap shooting sebagai berikut :

1) Hipotesis Nol (H0) : Tidak ada hubungan jump shoot terhadap shooting.

2) Hipotesis Kerja (Ha) : Ada hubungan jump shoot terhadap shooting.

Jika nilai signifikansi $>0,05$ maka H0 diterima, sedangkan jika nilai signifikansi $<0,05$ maka Ha diterima. Berdasarkan analisi korelasi menunjukkan bahwa koefisien korelasi sebesar $r=0,899$ dengan signifikansi 0,000 karena signifikansi variabel jump shoot terhadap prestasi lebih kecil dari 0.05, sehingga $\mathrm{H} 0$ ditolak, Ha diterima hipotesis dapat dinyatakan "Ada Hubungan Hasil Latihan Jump shoot terhadap Shooting"

2. Bank Shoot terhadap Shooting

Tabel 6. Bank Shoot Terhadap Shooting

Paired Samples Correlations

\begin{tabular}{|ll|r|r|r|}
\hline & & N & Correlation & \multicolumn{1}{c|}{ Sig. } \\
\hline Pair & Shooting pre \& & 10 & .625 & .054 \\
1 & Shooting post & 10 & .65 & \\
\hline
\end{tabular}

Hipotesis dalam penelitian tentang hubungan bank shoot terhadap shooting sebagai berikut :

3) Hipotesis Nol (H0) : Tidak ada hubungan bankshoot terhadap shooting.

4) Hipotesis Kerja (Ha) : Ada hubungan bankshoot terhadap shooting.

Jika nilai signifikansi >0,05 maka H0 diterima, sedangkan jika nilai signifikansi $<0,05$ maka Ha diterima. Berdasarkan analisi korelasi menunjukkan bahwa koefisien korelasi sebesar $r=0,625$ dengan signifikansi 0,054 karena signifikansi variabel jump shoot terhadap prestasi lebih kecil dari 0.05, sehingga H0 ditolak, Ha diterima hipotesis dapat dinyatakan “Ada Hubungan Hasil Latihan Bank shoot terhadap Shooting" 
3. Jump shoot dan Bank Shoot terhadap Shooting

Tabel 7. Jump Shoot dan Bank Shoot Terhadap Shooting

Test Statistics

\begin{tabular}{|l|r|}
\hline & $\begin{array}{c}\text { Selisih } \\
\text { Shooting }\end{array}$ \\
\hline Mann-Whitney U & 41.500 \\
Wilcoxon W & 96.500 \\
Z & -.679 \\
Asymp. Sig. (2-tailed) & .497 \\
Exact Sig. [2*(1-tailed & $.529^{\mathrm{a}}$ \\
Sig.)] &. \\
\hline
\end{tabular}

a. Not corrected for ties.

b. Grouping Variable: Kelompok

Jika nilai signifikansi >0,05 maka H0 diterima, sedangkan jika nilai signifikansi <0,05 maka Ha diterima. Hasil analisis dengan signifikansi 0,497, sehingga H0 ditolak dan Ha diterima hipotesis dapat dinyatakan “Ada hubungan Pengaruh Hasil Latihan Jump Shoot Dan Bank Shoot Terhadap Kemampuan Shooting Pemain Bola Basket Klub Mranggen Selection Basketball"

Hasil penelitian menunjukkan latihan Jump shoot hasil shooting pada peserta klub mranggen selection basketball. Setelah di beri perlakuan terdapat peningkatan hasil shooting adalah 5,30 dimana sebelumnya hanya 3,10. Melalui latihan jump shoot pemain mampu mengatur tenaga atau kekuatan dorongan bola dengan baik sehingga akurasi dalam melakukan shooting lebih terarah.

\section{KESIMPULAN}

Berdasarkan penelitian yang telah dilakukan tentang hubungan Pengaruh Hasil Latihan Jump Shoot Dan Bank Shoot Terhadap Kemampuan Shooting Pemain Bola Basket Klub Mranggen Selection Basketball, maka dapat disimpulkan ada hubungan yang signifikan antara hasil latihan jump shoot terhadap kemampuan shooting pemain bola basket klub mranggen selection basketball yang sedang dengan koefisien korelasi 0.899 dengan nilai signifikansi 0.000 .

Ada hubungan yang signifikan antara hasil latihan bank shoot terhadap terhadap kemampuan shooting pemain bola basket klub mranggen selection basketball yang sedang dengan koefisien korelasi 0.625 dengan nilai signifikansi 0.054 .

Ada hubungan yang signifikan terhadap atlet bola basket klub mranggen selection basketball yang kuat dengan nilai signifikasi 0.497 . 


\section{DAFTAR PUSTAKA}

Aryanto, B. (2018). Teknik Dan Taktik Dalam Permainan Bola Basket. Yogyakarta: UNY Press. Khoeron, N. (2017). Buku Pintar Basket. Jakarta: Anugrah .

Sugiyono. (2014). Metode Penelitian Kuantitatif Kualitatif Dan R\&D. Bandung : Alfabeta. Werdihatohadi, F. A. (2011). Menjadi pemain Bola Basket Hebat. Jakarta: Be Champion 